\title{
Responses of female rats to odors from familiar vs. novel males
}

\author{
W. J. CARR \\ E. R. Johnstone Training and Research Center, Bordentown, New Jersey 08505 \\ and
MARLA DEMESQUITA-WANDER, SANDRA RODDE SACHS, and PAMELA MACONI \\ Beaver College, Glenside, Pennsylvania 19038
}

\begin{abstract}
In a two choice odor-preference test, 14 female rats with monogamous mating experience reliably preferred $(p<.01)$ the odor from the male with whom they gained all their prior mating experience over the odor from a novel male. Earlier research indicated that polygamous females are indifferent to the two masculine odors. In sharp contrast, polygamous males prefer the novel female odor over the familiar female odor and monogamous males are indifferent to the two feminine odors. These sex-linked differences in olfactory preferences are related to differences in the mating strategies of male vs. female rats.
\end{abstract}

Many view mating behavior in laboratory rats as being largely under the male's control, the female's role being viewed as relatively passive and even somewhat reflexive. But this view is gradually changing, as recent research demonstrates that the female also exerts considerable control over the male's mating behavior (Doty, 1974). Thus, each member of the pair tends to constrain the behavior of the other in accord with its own sex-linked mating strategy. Some believe that these competing mating strategies evolved as a result of the male's low and the female's high level of parental investment in the young (Trivers, 1972; Williams, 1975, Chapter 11).

Among rats, one obvious difference between the masculine and the feminine mating strategies has to do with the selection of potential mates. In one mating session, rested males can achieve 5-10 ejaculations with a single female and 7-22 ejaculations with more than one female (Beach \& Jordan, 1956; Fisher, 1962; Fowler \& Whalen, 1961; Larsson, 1956). Since one ejaculation is sufficient to impregnate a female, it seems clear that males would maximize their progeny by disseminating their gametes to as many females as possible rather than by expending all their gametes on one female (Adler, 1978). Indeed, some believe that the masculine mating strategy exhibited by many species is more concerned with maximizing the number of females impregnated than with the females' genetic quality (Williams, 1975, p. 128).

This research was supported in part by HEW Research Grant MH24546. Marla DeMesquita-Wander is now at the Department of Educational Studies, the University of Delaware. Sandra Rodde Sachs is now at the Dental Department, Western Pennsylvania Hospital, Pittsburgh, Pennsylvania. Pamela Maconi is now at the Department of Social Services, Polk County, Des Moines, Iowa. Requests for reprints should be addressed to W. J. Carr, E. R. Johnstone Training and Research Center, Bordentown, New Jersey 08505.
Empirical support for such a mating strategy in male rats stems from the well documented Coolidge effect, that is, the tendency of a male that is sexually satiated to a particular female to resume copulating with a novel female (Beach \& Ransom, 1967; Bermant, Lott, \& Anderson, 1968; Cherney \& Bermant, 1970; Fisher, 1962; Fowler \& Whalen, 1961; Hsaio, 1965; Wilson, Kuehn, \& Beach, 1963). Although its determinants are not completely understood, some evidence suggests that the Coolidge effect is due, at least in part, to the greater excitatory value of olfactory stimuli emanating from the novel female relative to those emanating from the familiar female (Adler, 1978; Carr, Krames, \& Costanzo, 1970; Krames 1971; Krames \& Mastromatteo, 1973; Zucker \& Wade, 1968).

In contrast to the male's mating strategy of impregnating the maximum number of females, the female's strategy is aimed at maximizing the quality of her mate's gametes (Orians, 1969; Trivers, 1972) and/or the quality of environmental resources available to her (Williams, 1975, p. 130). As regards this strategy, we know that (1) female rats play a significant role in the selection of mates, (2) previous social experience influences their selection, and (3) the selection is mediated, at least in part, by olfactory stimuli emanating from competing males (Adler, 1978; Doty, 1974; French, Fitzpatrick, \& Law, 1972; McClintock \& Adler, in press; Peirce \& Nuttal, 1961; French, Note 1). Therefore, the purpose of the present investigation was to determine whether previous mating experience with a particular male influences the female's preference for the odor from that male vs. the odor from a novel male.

\section{METHOD}

Subjects

The subjects were 14 female rats of the Long-Evans strain 
(Perfection Breeders, Douglassville, Pennsyslvania). They were ovariectomized at 4 months of age, and 10 days later, each was housed with a single male of the same strain and age. The cages were made of hardware cloth and measured $25 \times 38 \times 71 \mathrm{~cm}$. The floors were covered with pinewood shavings. The animals were maintained in a temperature-controlled room $\left(21^{\circ} \mathrm{C}\right)$ on a $12: 12 \mathrm{light} /$ dark cycle, the lights going off at $1200 \mathrm{~h}$. Lab chow pellets and water were available constantly.

\section{Procedure}

Beginning at 6 months of age, each female subject received four weekly mating sessions with her male cagemate in their home cage. The females were rendered receptive by a subcutaneous injection of $.01 \mathrm{mg}$ estradiol followed in $72 \mathrm{~h}$ by an injection of $.4 \mathrm{mg}$ progesterone. During each session, the pairs were observed for $1 \mathrm{~h}$, beginning $6 \mathrm{~h}$ after the second injection. To eliminate unobserved mating behavior, the females were housed individually in separate cages during the 6-h period between the second injection and the beginning of the mating session. In 11 of the 14 cages, mating to one or more ejaculations was observed during the first or second session and thereafter. In the remaining three cages, mating to one or more ejaculations was observed during the third and fourth sessions.

Beginning 1 week after the last mating session, each subject received two 10-min preference tests (separated by 1 week) during which she could respond to the odor from her familiar male cagemate vs. the odor from a novel male. The preference tests were conducted in the subject's home cage while she was sexually receptive.

The preference testing technique has been described in detail and illustrated elsewhere (Carr, 1974). Briefly, the subject was presented with two cardboard cylinders $(10 \times 18 \mathrm{~cm})$ that for $1 \mathrm{~h}$ immediately preceding the test had housed either the subject's male cagemate or a novel male, that is, the cagemate of another subject. (Each male served once as a familiar male and once as a novel male.)

Just before testing, the males were removed from the cylinders, leaving benind urine, feces, and so on. A cardboard cap on each end of the cylinders prevented the subjects from entering, but a $5-\mathrm{cm}$ hole in the center of each cap permitted odor-laden air to pass through the cylinders and into the subject's home cage. The two cylinders were located in opposite rear corners of the cage. A cardboard atrium $(10 \times 13 \mathrm{~cm})$ was attached to the end of each cylinder exposed to the subject.

During the preference test, an experimenter recorded the time spent by the subject investigating each cylinder, that is, the number of seconds any part of its head extended inside the atrium attached to that container. During testing, the experimenter did not know which odor was associated with a given cylinder. New cylinders, caps, and atria were used for each subject's test, and a counterbalancing procedure was used to eliminate the effect of a possible position preference on the part of the subjects. Testing began $1 \mathrm{~h}$ after the onset of the dark phase of the light/dark cycle.

\section{RESULTS AND DISCUSSION}

The results of the experiment are shown in Table 1. During the 20-min preference test, the female subjects exhibited a reliable preference for the familiar male's odor over the novel male's odor [Wilcoxon matchedpairs signed-ranks test, $\mathrm{T}(14)=12, \mathrm{p}<.01$ ] . Twelve of the 14 females spent the majority of their investigation time with the familiar male's odor.
Table 1

Mean Time (Seconds) Spent by Female Rats Investigating Odors from Familiar vs. Novel Males

\begin{tabular}{|c|c|c|c|c|}
\hline \multirow[b]{2}{*}{ Test } & \multicolumn{2}{|c|}{ Male Odor } & \multirow{2}{*}{$\begin{array}{c}\text { Difference } \\
\text { Score }\end{array}$} & \multirow{2}{*}{$\begin{array}{c}\text { Preference } \\
\text { Ratio* }\end{array}$} \\
\hline & Familiar & Novel & & \\
\hline 1 & 34.5 & 25.6 & +8.9 & $9 / 5$ \\
\hline 2 & 34.4 & 24.6 & +9.8 & $9 / 5$ \\
\hline $1-2$ & 68.9 & 50.2 & +18.7 & $12 / 2 * *$ \\
\hline
\end{tabular}

*Defined as the number of subjects preferring the familiar male odor divided by the number preferring the novel male odor. ${ }^{* *} p<.01$

When coupled with the results of previous research, the present findings suggest that male and female rats differ radically in their responsiveness to the odors from familiar vs. novel sex partners. Moreover, the preference behavior exhibited by members of each sex seems congruent with the overall mating strategy characteristic of that sex.

Polygamous male rats prefer the odor from novel females over the odor from familiar females, but monogamous males are indifferent to the two feminine odors (Carr et al., 1970). In nature, the polygamous male's preference for the novel female odor would promote mating with such females, thereby satisfying the masculine mating strategy aimed at maximizing the number of females impregnated (Adler, 1978; Trivers, 1972; Williams, 1975). However, it is interesting to note that if polygamous males are interrupted during a mating session prior to the first ejaculation, they prefer the familiar female's odor (Krames \& Mastromatteo, 1973). The monogamous male's indifference to the two feminine odors may stem from the enhanced secondary reinforcing property of the familiar female's odor, which offsets the male's preference for the novel female's odor.

In sharp contrast, polygamous females are indifferent to the odors from familiar vs. novel males (Carr et al., 1970), but monogamous females prefer the odor from the familiar male with whom they gained all their mating experience (present experiment). This preference is congruent with the view expressed by Erickson (1978) that sexual fidelity is more characteristic of the feminine mating strategy than of the masculine mating strategy, especially in those species where the female makes the larger parental investment. Moreover, the present findings cast doubt on the view expressed by Ford and Beach $(1951$, p. 122) that male and female rats mate indiscriminately and that "feminine fidelity, where it occurs, appears to reflect male domination." No such domination was possible in the testing situation used here.

\section{REFERENCE NOTE}

1. French, D. Personal communication, February 28, 1973. 


\section{REFERENCES}

Adle R, N. T. On the mechanisms of sexual behaviour and their evolutionary constraints. In J. B. Hutchison (Ed.), Biological determinants of sexual behaviour. New York: Wiley, 1978.

BEACH, F. A., \& Jordan, L. Sexual exhaustion and recovery in the male rat. Quarterly Journal of Experimental Psychology, 1956, 8, 121-133.

BEACH, F. A., \& RANSOM, T. W. Effects of environmental variation on ejaculation frequency in male rats. Journal of Comparative and Physiological Psychology, 1967, 64, 384-387.

Bermant, G., LotT, D. F., \& Anderson, L. Temporal characteristics of the Coolidge effect in male rat copulatory behavior. Journal of Comparative and Physiological Psychology, $1968,65,447-452$.

CARR, W. J. Pheromonal sex attractants in the Norway rat. In L. Krames, P. Pliner, \& T. Alloway (Eds.), Advances in the study of communication and affect (Vol. 3). New York: Plenum Press, 1974.

Carr, W. J., Krames, L., \& Costanzo, D. J. Previous sexual experience and olfactory preference for novel versus original sex partners in rats. Journal of Comparative and Physiological Psychology, 1970, 71, 216-222.

Cherney, E. F., \& Bermant, G. The role of stimulus female novelty in the rearousal of copulation in male laboratory rats (Rattus norvergicus). Animal Behaviour, 1970, 18, 567-574.

Doty, R. L. A cry for the liberation of the female rodent: Courtship and copulation in rodentia. Psychological Bulletin, 1974, 81, 159-172.

Erickson, 'C. J. Sexual affiliation in animals: Pair bonds and reproductive strategies. In J. B. Hutchison (Ed.), Biological determinants of sexual behaviour. New York: Wiley, 1978.

Fisher, A. E. Effects of stimulus variation on sexual satiation in the male rat. Journal of Comparative and Physiological Psychology, 1962, 55, 614-620.

Ford, C. S., \& BeACH, F. A. Patterns of sexual behavior. New York: Harper \& Row, 1951.

Fowler, H., \& Whalen, R. E. Variation in incentive stimulus and sexual behavior in the male rat. Journal of Comparative and Physiological Psychology, 1961, 54, 68-71.

French, D., FitzPatrick, D., \& Law, O. T. Operant investigation of mating preference in female rats. Journal of Comparative and Physiological Psychology, 1972, 81, 226-232.

Hsiao, S. Effect of female variation on sexual satiation in the male rat. Journal of Comparative and Physiological Psychology, $1965,60,467-469$.

Krames, L. Sexual responses of polygamous female and monogamous male rats to novel sex partners after sexual cessation. Journal of Comparative and Physiological Psychology, 1971, 77, 294-301.

Krames, L., \& Mastromatteo, L. A. Role of olfactory stimuli during copulation in male and female rats. Journal of Comparative and Physiological Psychology, 1973, 85, 528-535.

LARSSON, K. Conditioning and sexual behavior. Stockholm: Almqvist \& Wiksell, 1956.

McClintock, M. K., \& Adler, N. T. The role of the female during copulation in the wild and domestic Norway rat (Rattus norvegicus). Behaviour, in press.

Orians, G. H. On the evolution of mating systems in birds and mammals. American Naturalist, 1969, 103, 589-603.

Peirce, J. T., \& NutTal, R. L. Self-paced sexual behavior in the female rat. Journal of Comparative and Physiological Psychology, 1961, 54, 310-313.

Trivers, R. L. Parental investment and sexual selection. In B. Campbell (Ed.), Sexual selection and the descent of man, 18711971. Chicago: Aldine, 1972.

Williams, G. C. Sex and evolution. Princeton: Princeton University Press, 1975.

Wilson, J. R., Kuehn, R. E., \& BeAch, F. A. Modification in the sexual behavior of male rats produced by changing the stimulus female. Journal of Comparative and Physiological Psychology, 1963, 56, 636-644.

ZuCKer, I., \& W ADE, G. Sexual preferences of male rats. Journal of Comparative and Physiological Psychology, 1968, 66, 816-819.

(Received for publication May 13, 1979.) 